\title{
Unit of Linear Acceleration
}

National Cancer Institute

\section{Source}

National Cancer Institute. Unit of Linear Acceleration. NCI Thesaurus. Code C48034.

An indication of the type of unit of measure being used to express linear acceleration. 